\title{
Using multidimensional poverty measures in impact evaluation: Emergency housing and the "declustering" of disadvantage
}

\author{
Ann Mitchell ${ }^{*}$ and Jimena Macció** \\ *Department of Economics, Pontificia Universidad Católica Argentina, Buenos Aires, \\ Argentina \\ ** Department of Economics, Pontificia Universidad Católica Argentina, Buenos Aires, \\ Argentina
}

Correspondence address: Ann Mitchell, Department of Economics, Pontificia Universidad Católica Argentina, Alicia Moreau de Justo 1400, Ciudad Autónoma de Buenos Aires (1425), Argentina. Email: annmitchell@uca.edu.ar. (54-11) 4349-0200, x7069. Orchid ID: https://orcid.org/0000-0003-0122-3436

Ann Mitchell has a $\mathrm{PhD}$ in Economics from the University of Maryland, USA and is Professor of Social Development in the Department of Economics at the Pontificia Universidad Católica Argentina in Buenos Aires, Argentina. She specializes in the analysis of diverse social topics, including multidimensional poverty, education, civil society and the evaluation of social programmes.

Jimena Macció has a doctorate in Economics from the Universidad de Buenos Aires and is Professor of Econometrics in the Department of Economics of the Pontificia Universidad Católica Argentina. She also holds a position in the Unit for Evaluation of Educational Quality and Equity of the Government of the City of Buenos Aires. She specializes in quantitative analysis of social topics, with a focus on multidimensional poverty and education.

\section{Acknowledgements}

The authors are grateful to María Emma Santos, Edoardo Masset, Ana Vaz, Bilal Malaeb, Sabina Alkire, Andy Mckay and Nicolai Suppa for their valuable comments on previous versions of this paper. 


\section{Using multidimensional poverty measures in impact evaluation: Emergency housing and the "declustering" of disadvantage}

Abstract: During the past two decades, impact evaluation and multidimensional poverty measurement have gained increasing relevance in development practice and research. The objective of this paper is to propose empirical strategies for using the multidimensional poverty measures proposed by Alkire and Foster (2011) in impact evaluation. The principal argument for taking this approach is that it provides a means for assessing the effects of social programmes on the simultaneous occurrence or joint frequency of deprivations, what Wolff and deShalit (2007) call the "clustering" of disadvantage. These strategies are applied to the evaluation of the NGO TECHO's emergency housing programme in the informal settlements of Buenos Aires, Argentina. The results show that the programme produces a large reduction in the simultaneous occurrence of disadvantages. The incidence of multidimensional deprivation drops significantly and the multidimensional poverty measure falls by half. Privacy, interpersonal relations and psychological health are the dimensions that contribute the most to explaining the decline in multidimensional deprivation. Sensitivity analyses demonstrate the robustness of the results to changes in the criteria used to construct the multidimensional poverty measure.

Keywords: impact evaluation, multidimensional poverty, housing, capability approach, clustering of disadvantage

JEL classification: C13, I32, R21

\section{Introduction}

During the past two decades, impact evaluation has gained growing relevance in development research and practice (Duflo, Glennerster and Kremer 2008; White 2014). Governments and civil society organizations increasingly seek to have a solid evidence base when designing and implementing social programmes. Concurrently, we have observed a growing consensus that poverty is a multidimensional concept and an expanding use of multidimensional poverty measures (Narayan et al. 2000; Atkinson 2003; UNDP and OPHI 2019a). The work of Amartya Sen (1992; 1999) and others working within the capability approach has been instrumental in shifting the conceptual 
notion of poverty from lack of income to the deprivation of basic capabilities. Although there is an ongoing debate on how to operationalize the concept of multidimensional poverty (Pattanaik and $\mathrm{Xu} 2018$ ), the dual-cut-off counting approach proposed by Alkire and Foster (2011) has become the most widely used method. Many nations worldwide have adopted official multidimensional poverty measures using the Alkire-Foster method (UNDP and OPHI 2019a) and estimates of the Global Multidimensional Poverty Index based on this method have been published for more than 100 countries (UNDP and OPHI 2019b).

We aim to situate this paper in the intersection between the impact evaluation and the multidimensional poverty measurement literature. Its objective is to propose empirical strategies for using the Alkire-Foster multidimensional poverty measure in impact evaluation. The principal argument for taking this approach is that it provides a means for assessing the effects of social programmes on the simultaneous occurrence or joint frequency of deprivations, what Wolff and de-Shalit (2007) call the "clustering" of disadvantage. These authors argue that the interrelation between functionings - the things that people can be and do-causes disadvantages and risks to "compound each other and cluster together" (Wolff and de-Shalit 2007, 10). A poor mother who lacks access to childcare services cannot obtain a job; she cannot obtain medical care when her child is sick without access to bus services; and she cannot benefit from a publicly provided housing programme if she lacks schooling and basic knowledge needed to apply for benefits. Similarly, people living in a house with a leaking roof or severe overcrowding will likely wake up frequently at night, experience daytime sleepiness, feel concern about the security of their dwelling, producing conflict between household members and negatively affecting physical and mental health. If causal pathways bind disadvantages together, then social programmes that produce a "declustering" of disadvantage could 
produce benefits that go beyond improvements in multiple wellbeing dimensions individually, providing an argument for evaluating treatment effects on the simultaneous occurrence of deprivation. We argue that the Alkire-Foster method, which identifies as poor those persons (or households) who experience an accumulation of deprivations that surpasses a specified threshold, effectively captures this concept of clustering of disadvantages.

A second argument for employing the Alkire-Foster measure in impact evaluation is to obtain a summary measure of overall treatment effects. Consolidated outcome measures are increasingly used in the impact evaluation literature as a means for resolving the increased probability of type I error (false positive) when carrying out multiple hypothesis tests (Kling, Liebman and Katz 2007; Anderson 2008). The Alkire-Foster method can be used to construct a summary outcome measure based on normative criteria (with regard to the selection of wellbeing dimensions, indicators, thresholds, weights, etc.) as opposed to purely empirical methods.

Finally, the Alkire-Foster measures are additively decomposable by dimension. We show that this property is useful for analysing how social programmes alter the extent to which different wellbeing dimensions contribute to the simultaneous occurrence or clustering of deprivations.

To illustrate how to apply the Alkire-Foster method to impact evaluation, we use as an empirical example an evaluation of the NGO TECHO's emergency housing programme. This programme, which is currently being applied in 19 Latin American and Caribbean countries, provides a basic dwelling on-site to households living in informal settlements. We extend the evaluation applied in Buenos Aires, Argentina using a quasiexperimental "pipeline" design (Mitchell, Macció and Mariño Fages 2019) to a multidimensional framework. Our results show that the TECHO programme produced a 
large declustering of disadvantage in dimensions related to the built environment. The incidence of multidimensional deprivation drops significantly and the multidimensional poverty measure falls by more than half. Privacy, interpersonal relations and psychological health are the dimensions that contribute the most to explaining the decline in multidimensional deprivation.

The article contributes to a growing number of papers that apply lessons of the human development and capability approach and tools of multidimensional poverty measurement to the evaluation of social programmes. For example, Muñiz Castillo (2014) uses human development concepts as a basis for evaluating the effects of development projects on human autonomy. Pham (2018) proposes using the capability approach as a framework for evaluating community-driven development projects and outlines some challenges faced in operationalizing the approach. In addition, a number of recent papers apply the Alkire-Foster method to impact evaluation (Loschman, Parsons and Siegel 2015; Song and Imai 2018; Masset and García Hombrados 2019; Vaz, Malaeb and Quinn 2019; and Seth and Tutor 2019). Our paper makes a significant contribution to this literature by proposing econometric methods for estimating treatment effects on the Alkire-Foster measure that more adequately capture the method's dual cut-off approach.

The paper also contributes to the literature on the impact of emergency housing. Simonelli et al. (2013) showed that TECHO's programme in Buenos Aires was associated with reductions in levels of stress and dissatisfaction with housing and improvements in sleep quality and perception of quality of life. Their study, however, was based on a nonexperimental before-after methodology and a relatively small sample of households. The experimental evaluation of TECHO applied in Mexico, El Salvador and Uruguay by Galiani et al. (2016) showed that the TECHO programme produced increases in subjective measures of quality of life and housing satisfaction and a reduction in the 
incidence of diarrhoea in children (in Mexico and El Salvador), but had no effect on the possession of durable goods, complementary housing investments, robbery, fertility, income or labour market outcomes. A limitation of that evaluation was that it focussed primarily on measuring the programme's effects on income and other means for achieving wellbeing, rather than on final ends, or "what it is worth seeking for its own sake" (Richardson 2015, 163). Mitchell, Macció and Mariño Fages (2019), guided by the lessons of the capability approach, sought to measure treatment effects on deprivations in the space of human functionings (to be free of disease, to feel secure, to experience privacy, to enjoy adequate sleep, to have opportunities to socialize, etc.). We expand upon their analysis by assessing the programme's effects on the simultaneous occurrence of housing-related deprivations.

The paper is structured as follows. Section two describes TECHO's emergency housing programme and the evaluation design and results by dimension. Section three introduces the Alkire-Foster method, demonstrates how to use the method to construct a summary outcome measure and presents the statistical strategies used to estimate treatment effects on the multidimensional deprivation measures. Section four analyses the empirical results. Section five concludes.

\section{Evaluation of TECHO's emergency housing programme}

TECHO's programme provides a basic dwelling on-site to families who live in informal settlements and experience a severe deficit in the size and quality of housing. The 18square-meter dwelling is made of prefabricated wood panels, has an insulated tin roof and rests on 15 pilings that elevate the house from ground humidity and flooding. The programme does not provide water, sanitation or electrical connections. The cost of materials for each unit, which is constructed by small teams of volunteers together with future residents, is approximately US $\$ 1,000$ dollars. 
TECHO-Argentina's participant selection process consists of first conducting in each neighbourhood a detection survey that collects information on the household's sociodemographic characteristics, economic situation, access to public services and size and quality of the dwelling. This information is then used to classify households according to their level of need. Households considered to have high and medium-high need are eligible to participate in the programme. Before construction the household head must sign a contract stating that she or he will pay around $10 \%$ of the cost of materials, attend preconstruction neighbourhood meetings and prepare the plot of land before construction.

The evaluation of TECHO-Argentina applied a quasi-experimental "pipeline" design (Coleman 1999; Bali Swain and Varghese 2009; Deininger and Lui 2013) consisting of an ex post comparison between treated households and a control group of households that had been selected for the programme but had not yet received treatment (Mitchell, Macció and Mariño Fages 2019). The households were chosen from 34 informal settlements in the peri-urban areas of Buenos Aires. All of the settlements satisfied TECHO's operational definition of informal settlement: neighbourhoods with at least eight families in which at least half of the households do not have a formal land title nor formal access to at least two basic services (water, sanitation and electricity) (TECHO 2016).

The treatment group is comprised of the households who received the TECHO house during the first half of 2014 and the control group is comprised of the households who received the house during the first half of 2015. The same participant selection process was applied to treatment and control group households. Baseline surveys were conducted during approximately the same range of months during each year (to reduce possible effects of seasonality) and were applied to each household between one and four 
weeks before construction. The survey respondent was the person who spent the most time in the home and was usually the mother of the principal family unit. Each survey respondent knew that their household had been selected for the programme at the time of the baseline survey. The treatment group follow-up survey data was collected approximately one year after receiving the dwelling. Approximately one-third of the treated households replaced their dwelling with the TECHO house and two-thirds used it as an additional room.

Mitchell, Macció and Mariño Fages (2019) show that the treatment and control groups are well balanced. The results of t-tests indicate that there is not a statistically significant difference between groups for any of the 17 pre-treatment household characteristics considered and in all cases the value of the normalized difference is quite low, indicating that regression analysis is a valid method for estimating average treatment effects (see Imbens 2015).

Based on a review of the broad literature on the effects of housing on wellbeing, ${ }^{1}$ Mitchell, Macció and Mariño Fages (2019) constructed 31 impact indicators in the dimensions of physical health, psychological health, sleep, privacy, interpersonal relations and security. The following linear regression equation was used to estimate the average treatment effect on the treated, $\delta$, for outcomes of interest, $Y_{i}$ :

$$
Y_{i}=\alpha+\beta X_{i}+\gamma Z_{i}+\delta T_{i}+\varepsilon_{i}
$$

where $T_{i}$ is an indicator of treatment, $X_{i}$ is a set of observed household characteristics, $Z_{i}$ is a set of neighbourhood dummy variables and $\varepsilon_{i}$ is an error term reflecting unobserved characteristics that also affect $Y_{i}{ }^{2}$ Robust standard errors with neighbourhood clustering

\footnotetext{
${ }^{1}$ See, for example Thomson et al. (2009) and Newman (2008).

${ }^{2}$ The linear probability model is widely used in the evaluation literature to estimate the average treatment effect on binary outcome measure in experimental or quasi-experimental evaluations (Angrist and Pischke 2009).
} 
were used for all regressions.

The evaluation results indicate that the TECHO programme had a large direct effect on increasing the size and quality of housing. The prevalence of critical overcrowding ( $>3$ persons per room) fell from $37 \%$ to $13 \%$ and there was a marked decline in the share of rooms with problems in the floor, walls and roof. ${ }^{3}$ These improvements in housing caused large and statistically significant effects on indicators of privacy, security, interpersonal relations and psychological health. In physical health, the prevalence of cough and congestion declined. Sleep indicators also improved but the effects were not statistically significant after adjusting for multiple hypothesis testing.

The authors, moreover, analysed the robustness of the results to possible biases that may have been caused by non-random attrition, neighbourhood differences and seasonal differences in the time of the survey, and find no evidence that these factors were driving the results. They also show that the results based on the propensity score matching procedure are similar to those based on the pipeline regressions in terms of magnitude and statistical significance. In addition, the results of a falsification test in which treatment group post-treatment outcomes were replaced with baseline values indicate that the treatment effect disappears for all of the indicators in which a statistically significant effect had been found.

These findings demonstrate the positive effects of the TECHO programme on reducing deprivation in individual measures of housing related functionings. They do not make progress, however, on understanding how these improvements combine to produce

\footnotetext{
${ }^{3}$ It is important to note that the programme did not produce a statistically significant change in household size. While many families experienced changes in household composition between the baseline and follow-up surveys, most changes were due to common demographic changes such as births, change in partners and young adults leaving home.
} 
a declustering of disadvantage. Does the programme reduce the simultaneous occurrence of deprivations? The following section proposes methods for responding to this question.

\section{Applying the Alkire-Foster method to impact evaluation}

In this section, we present empirical strategies for applying the Alkire-Foster method to impact evaluation. We construct a composite outcome measure in dimensions related to the built environment and propose statistical methods for obtaining unbiased estimates of treatment effects on this measure.

\subsection{Construction of an Alkire-Foster measure comprised of outcome indicators}

Alkire and Foster's counting approach to multidimensional poverty measurement entails identification and aggregation stages. In the identification stage, one must select the dimensions of analysis and one or more wellbeing indicators within each dimension. For each indicator it is necessary to choose a deprivation cut-off, which expresses the minimum level of achievement necessary to be not deprived in that indicator, and a relative weight, such that the sum of the indicator weights equals one. The deprivation score, $c_{i}$, is the weighted share of deprivations experienced by household (or person) $\mathrm{i}$. Then it is necessary to set the poverty cut-off $\mathrm{k}$, which is the proportion of weighted deprivations that a household must experience in order to be considered multidimensionally poor. A household with a deprivation score greater than or equal to the poverty cut-off $\left(c_{i} \geq k\right)$ is identified as multidimensionally poor. Then let $c=\left[c_{i}\right]$ be a deprivation score vector in which $c_{i}$ is the deprivation score of household $\mathrm{i}$ and $c(k)=\left[c_{i}(k)\right]$ be a censored deprivation score vector in which $c_{i}(k)=c_{i}$ if household $\mathrm{i}$ is multidimensionally poor and $c_{i}(k)=0$ otherwise.

The aggregation stage of the Alkire-Foster method is based on the extension of the FGT family of unidimensional poverty measures (Foster, Greer and Thorbecke 1984) to the case of multiple deprivations. We employ three Alkire-Foster measures in 
this paper. ${ }^{4}$ The multidimensional headcount ratio $H$ represents the proportion of households identified as multidimensionally poor:

$$
H=\frac{q(k)}{n}
$$

where $q(k)$ is the number of multidimensionally poor households and $n$ is the total number of households. The intensity of multidimensional poverty $A$ is defined as the average share of weighted indicators in which poor households are deprived:

$$
A=\sum_{i=1}^{q} \frac{c_{i}(k)}{q(k)}
$$

This measure captures the breadth of deprivations experienced by multidimensionally poor households. The adjusted headcount measure $M_{0}$ is calculated as the product of $H$ and $A$ :

$$
M_{0}=H A=\frac{q}{n} \frac{1}{q} \sum_{i=1}^{q} c_{i}(k)=\frac{1}{n} \sum_{i=1}^{n} c_{i}(k)
$$

$M_{0}$ measures the sum of the weighted deprivations experienced by critically deprived households, divided by the maximum number of deprivations that could be experienced by all households if all households were deprived in all indicators. This measure rises with increases in either the incidence or the intensity of multidimensional poverty.

Within the Alkire-Foster framework, the unit of identification is most commonly the person or the household. The natural choice when applying the method to impact evaluation is to use the unit of analysis corresponding to the programme's beneficiaries (for example, the person for an education programme or the household for an income transfer programme). As the TECHO programme works with families, we use the household as the unit of identification.

\footnotetext{
${ }^{4}$ When the wellbeing indicators used to construct the multidimensional poverty measure are cardinal, it is also possible to compute the Adjusted Poverty Gap $M_{1}$ and the Adjusted FGT measure $M_{2}$ (see Alkire and Foster 2011).
} 
When applying the Alkire-Foster method to impact evaluation, it is reasonable to employ the impact dimensions and indicators identified in the theory of change, evidence on the outcomes most valued by participants and a review of the literature. In this way, the Alkire-Foster framework can be used to measure a programme's effect on the simultaneous occurrence of deprivation in multiple outcome dimensions. An alternative approach — used, for example, by Masset and Garcia Hombrados (2019) and Song and Imai (2018) - is to measure treatment effects on an existing official national or global multidimensional poverty measure. This strategy would be relevant only if one expects the programme to have an effect on the dimensions and indicators that comprise the official multidimensional poverty measure. As global poverty measures are developed with the goal of making poverty comparisons across countries, which vary greatly with regard to data availability and living standards (Alkire and Jahan 2018), it is likely that many socially beneficial programmes would not necessarily alter a global or even a national multidimensional poverty measure and, in fact, are not designed to do so. It is our opinion that both strategies are valid and the choice depends on the purpose of applying the Alkire-Foster to impact evaluation. As our objective is to construct a parsimonious composite outcome measure in which each indicator represents a distinct facet of deprivation related to the built environment, we chose to select two indicators within each of six outcome dimensions from the list of 31 impact indicators employed by Mitchell, Macció and Mariño Fages (2019).

In cases in which it is necessary to select a subset of indicators from a longer list of outcome measures already employed in a unidimensional analysis (as in our case), it is important to establish criteria for guiding this selection so as to avoid a problem of "cherry picking." It may also be useful to show that the p-values of the treatment effects 
on the selected impact indicators are "well-distributed" within a ranking of p-values for all possible impact measures or carry out indicator selection robustness tests.

The following are criteria relevant for guiding the selection of outcome indicators. First, the Alkire-Foster measure should include only one indicator for measuring each type of deprivation. It is common in the evaluation literature to use two or more impact indicators as proxies for measuring the same underlying outcome or that vary only with regard to the threshold level, reference period, or intensity. Whereas this practice will only tend to generate a problem of multiple hypothesis testing when measuring treatment effects on individual outcome measures, it could cause a more serious problem of double counting in multidimensional poverty measurement. Second, it is relevant to use practical criteria, such as the inclusion of indicators less subject to measurement error or with fewer missing values. This point is particularly important because one can calculate the AlkireFoster measure only over cases that do not have missing values for any of the indicators that comprise the measure. Third, there may be a preference for excluding indicators not defined for a subgroup of households (for example, households without children), as otherwise, it would be necessary to assume that the corresponding households are not deprived in that indicator. This is a problem encountered, for example, by Seth and Tutor (2019) and Vaz, Malaeb and Quinn (2019). Fourth, there are also arguments for prioritizing objective over subjective measures to avoid a problem of what Sen (1985) calls "adaptive preferences" whereby people who experience prolonged periods of deprivation become satisfied with low levels of objective wellbeing. While this list of criteria is not exhaustive, it aims to identify a number of relevant issues.

[Table 1 near here]

Following these criteria, we construct an Alkire-Foster measure in dimensions related to the built environment. Table 1 presents the control and treatment group baseline 
mean and standard deviation for each of the indicators that comprise this measure, followed by the treatment group ex post mean and standard deviation, the between group baseline difference and the treatment effect estimated using equation (4). These estimates are based on information on a total of 546 households (301 control group and 245 treatment group households). ${ }^{5}$ The results of the t-test of the difference in baseline means indicate that there is a statistically significant difference between groups only in the indicators of joint pain and frequent conflict due to lack of space. The results presented in the last column show that the TECHO programme had a statistically significant effect on all of the indicators that comprise the Alkire-Foster measure except for the incidence of joint pain and the measure of insufficient sleep quantity. In order to test the sensitivity of the results to the choice of indicators, section 4.2 presents robustness tests based on the random selection of indicators.

A variety of different approaches can be used to assign a weight to each deprivation indicator, ranging from rankings provided by household surveys or participatory processes to data driven approaches (Decancq and Lugo 2013). When all dimensions are equally important or no information is available to justify an alternative set of weights, it is common to apply equal weight to all dimensions and to all indicators within each dimension. We adopt this approach and present the results of robustness tests using alternative weighting structures.

A final normative choice is the selection of the poverty threshold, which is the weighted share of deprivations a household (or person) must experience to be identified as multidimensionally poor. At one extreme, a household could be identified as multidimensionally poor if deprived in at least one indicator (union approach) and at the

\footnotetext{
${ }^{5}$ The need to drop all cases with missing data for any of the indicators that comprise the AlkireFoster measure led to the loss of 51 control and 48 treatment group households.
} 
other extreme, identified as poor if deprived in all indicators (intersection approach). When available it is useful to employ information from participatory processes on the number of deprivations considered to constitute a critical level of disadvantage.

We set the poverty threshold for our Alkire-Foster measure at 33\%, which means that households deprived in at least four of the twelve indicators are identified as multidimensionally deprived. Our argument for employing an intermediate value is that if a household faces a limited number of deprivations, a functioning in one dimension could help household members to cope with deprivations in other dimensions. For example, strong interpersonal relations and sound psychological health could enable family members to deal with the lack of privacy, frequent sleep interruptions and physical insecurity associated with living in an inadequate dwelling. Deprivations in three indicators would not constitute a situation of multidimensional poverty. However, if a family member were to become ill or the household were to suffer a robbery, these situations could cause the household to reach a critical state of deprivation. In addition, we present robustness tests using a broad range of alternative poverty cut-offs.

[Figure 1 near here]

Figure 1 presents the distributions of the deprivation score $c_{i}$ and the censored deprivation score $c_{i}(k)$, constructed using the baseline data for the full sample of treatment and control households. Only $5 \%$ of the households have no deprivations, while no households are deprived in all indicators. When the threshold is applied, 55\% of the households are identified as multidimensionally poor. 


\subsection{Estimating treatment effects on the Alkire-Foster measures}

In this subsection we present the statistical methods used to estimate the effects of treatment on the Alkire-Foster measures $H, A$ and $M_{0}{ }^{6}$ An initial approach for measuring the treatment effect on $H$ is to replace the outcome variable $Y_{i}$ in equation (4) with a binary indicator of the household's poverty status, $h_{i}=1$ if household $\mathrm{i}$ is multidimensionally poor and $=0$ otherwise.

$$
H: \quad h_{i}=\alpha+\boldsymbol{\beta} X_{i}++\gamma Z_{i}+\delta_{1} T_{i}+\varepsilon_{i}
$$

Similarly, by replacing $Y_{i}$ with the deprivation score $c_{i}$ and estimating the regression over multidimensionally poor households we can obtain an estimate of the treatment effect on the measure of the intensity of multidimensional poverty $A$.

$$
A: \quad c_{i}=\alpha+\boldsymbol{\beta} X_{i}++\gamma Z_{i}+\delta_{2} T_{i}+\varepsilon_{i}, \quad c_{i} \geq k
$$

Finally, by replacing $Y_{i}$ with the censored deprivation score $c_{i}(k)$ we can obtain an estimate of the treatment effect on the adjusted headcount $M_{0}$

$$
M_{0}: \quad c_{i}(k)=\alpha+\boldsymbol{\beta} X_{i}++\gamma Z_{i}+\delta_{3} T_{i}+\varepsilon_{i}
$$

According to these specifications, the coefficient $\delta_{1}$ would provide an estimate of the treatment effect on $H, \delta_{2}$ an estimate of the treatment effect on $A$ and $\delta_{3}$ an estimate of the treatment effect on $M_{0}$. In fact, if one estimates simplified versions of these three regression equations in which the indicator of treatment is the only explanatory variable, the estimated treatment effects $\left(\delta_{1}, \delta_{2}\right.$ and $\left.\delta_{3}\right)$ are equal, respectively, to the absolute difference between the treatment and control groups in the values of measures $H, A$ and $M_{0}$ calculated using equations (1) through (3).

\footnotetext{
${ }^{6}$ Alkire et al. (2015) propose a framework for studying the determinants of multidimensional poverty at both the micro and macro levels using the General Linear Model (GLM) (Papke and Wooldridge 1996). A GLM regression with the deprivation score $c_{i}$ as the dependent variable, however, does not allow one to model the censoring at the poverty threshold, thereby neglecting the defining characteristic of the Alkire-Foster method.
} 
However, coefficient estimates based on OLS regressions of the last two equations ( 6 and 7) may be biased, due to truncation of the dependent variable in equation (6) and censoring of the dependent variable in equation (7). ${ }^{7} \mathrm{We}$, therefore, also present estimates of the treatment effect on $M_{0}$ using the truncated inflated beta regression model proposed by Pereira, Botter and Sandoval $(2012,2013) .{ }^{8}$ This is a mixture model that combines a trinomial distribution with probability masses at 0 , $\tau$, and 1 and a beta distribution defined over the interval $(\tau, 1)$. The truncated inflated beta regression model can be estimated in Stata using the betamix command developed by Gray and Hernandez Alava (2018). 9.

The choice of a two-part truncated inflated beta regression model implies recognizing that the processes causing a household (or person) to be identified as not multidimensionally poor $\left(c_{i}<k\right)$ may be different from the processes generating the accumulation of deprivations above the poverty threshold. Each part of the two-part model aims to explain $c_{i}$ over a different portion of its distribution: the first part models the identification of households as non-poor (the lower part of the distribution of $c_{i}$ ),

\footnotetext{
${ }^{7}$ None of the recent studies which measure treatment effects on the Alkire-Foster measures (Loschman, Parsons and Siegel 2015; Song and Imai 2018; Masset and García Hombrados 2019; Vaz, Malaeb and Quinn 2019; and Seth and Tutor 2019) take into account this potential source of bias in the estimation of treatment effects on $\mathrm{M}_{0}$.

${ }^{8}$ Pereira, Botter and Sandoval (2013) use this model to analyze the determinants of monthly credit card payments as a proportion of the total bill. This variable is discreet at 0 (no payment made), $\tau$ (payment made for the minimum amount established by the bank) and 1 (total bill paid) and continuous over the interval $(\tau, 1)$ (payment made for a proportion of the total bill above the minimum payment). No payments are made for values in the interval $(\tau, 1)$. This variable is very similar to the censored deprivation score used to calculate $M_{0}$.

${ }^{9}$ These authors, following the literature on mixture models (Smithson and Verkuilen 2012, among others), extend the model presented by Pereira, Botter and Sandoval to allow for the mixture of $\mathrm{C}$ beta distributions, which can be used to capture multimodality or overcome misspecification problems. This method is useful for modelling bounded variables that have a gap between the upper or lower boundary and the continuous part of the distribution, as is the case of the censored deprivation score. Moreover, it allows for observations on the limit values 0 or 1 and at the truncation parameter $\tau$. In our application, we have set a lower bound of $0, \tau=0.333$ and modelled one component for the beta distribution.
} 
while the second models the accumulation of deprivations above the threshold (the upper part of the distribution). We argue that there is a theoretical justification for using a twopart approach. Just as different processes may be needed to explain the generation of income at different points in the distribution (say, work-related income at the bottom of the distribution and rent-related income at the top), it is reasonable to argue that the factors associated with deprivation among the highly deprived may differ from those associated with deprivation among the least deprived.

An alternative and perhaps more straightforward justification for the use of a twopart model is that the defining characteristic of the Alkire-Foster measure- the censoring of scores below the poverty threshold - produces a two-part structure: one part to model multidimensional poverty status and another to model the proportion of deprivations above the threshold. We argue that his two-part structure should be modelled explicitly when attempting to analyse the determinants of multidimensional poverty.

Alkire et al. (2015) present a discussion of a one- versus two-part approach for estimating cross-sectional macro regressions in which the dependent variable is $H$ or $M_{0}$ measured at the provincial, country or other population subgroup level. In these models $H$ and $M_{0}$ are proportions that can take on any value in the $(0,1)$ interval as well as the boundary values of 0 and 1 . The authors support the use of a one-part model because they consider the boundary values of 0 (zero poverty) and 1 (full poverty), as well as all values in between, to be characterized by the same theoretical mechanism. The two-part model that we propose here is different in the sense that it aims to estimate a micro regression for $M_{0}$ and the two parts are used to model the discrete dichotomous variable classifying households as poor or non-poor and the accumulation of deprivations above the poverty threshold, thereby capturing the defining characteristic of the Alkire-Foster measure. 


\section{Multidimensional evaluation results}

This section is divided in three subsections. The first presents the estimated treatment effects on the Alkire-Foster measures. The second analyses the robustness of the results to changes in the selected indicators, indicator weights and poverty threshold. The third presents a dimensional decomposition of the multidimensional poverty measure.

\subsection{Treatment effects on the Alkire-Foster measures}

We begin the analysis of the programme's effect on multidimensional deprivation by comparing the distributions of the deprivation score $c_{i}$ and the censored deprivation score $c_{i}(k)$ disaggregated by treatment status. Figure 2 shows that the TECHO programme produces a leftward shift in the distribution of $c_{i}$. As a result, the percentage of non-poor households is twice as high in the treated households $(62 \%)$ than in the control group (31\%).

[Figure 2 near here]

Table 2 presents the results of the estimation of the effects of the TECHO programme on the three Alkire-Foster measures. The results based on OLS regressions indicate that the TECHO programme caused the percentage of households deprived in at least four weighted indicators to fall by 29 percentage points. Only $41 \%$ of treated households experience a critical accumulation of housing-related deprivations one year after receiving the TECHO house, compared with $69 \%$ of control group households. The intensity measure $A$ also declined by approximately 9 percentage points. Whereas at baseline the multidimensionally poor were, on average, deprived in half of the weighted indicators, after treatment this proportion fell to $41 \% .{ }^{10}$ The results based on the truncated

\footnotetext{
${ }^{10}$ When interpreting the effect of treatment on $A$ it is important to recall that, since poverty intensity is equal to the average deprivation score of poor households, when the multidimensional headcount also declines, the share of weighted deprivations is averaged over a smaller and poorer proportion of households. For this reason, $A$ tends to change relatively slowly.
} 
inflated beta regression indicate that the TECHO programme caused $M_{0}$ to drop by approximately half from 0.347 to 0.172 . Note that this estimate is slightly lower than that based on an OLS regression. Among the households who left multidimensional deprivation after receiving the TECHO house, the three deprivation indicators that declined the most are stress due to conflict (which fell by 48 percentage points), concern that the dwelling could collapse (40 percentage point drop) and never receive friends in home or feels uncomfortable doing so (39 percentage point drop).

[Table 2 near here]

\subsection{Robustness analysis}

When measuring the effects of an intervention on multidimensional poverty — as with any type of poverty comparisons (Ravallion 1992) — it is essential to assess if the results are robust to changes in the normative choices made when constructing the measure. In this section, we present the results of robustness tests on the selection of indicators, indicator weights and the poverty threshold. For all of the tests we present estimates of the treatment effects on $M_{0}$ based on both an OLS regression and the truncated inflated beta regression model.

\section{[Table 3 near here]}

To test the sensitivity of the results to the choice of indicators we constructed four alternative Alkire-Foster measures by randomly selecting two indicators within each dimension from our original list of 31 indicators (Table 3). The results based on the truncated inflated beta regression show that the treatment effect on $M_{0}$ is somewhat lower for three of the alternative specifications than for the original model but slightly higher in one case (test 3). The substantive results, however, do not change. For all of the tests the treatment effect on $M_{0}$ is statistically significant at the $1 \%$ significance level. 
In the second set of tests, we altered the dimension weights used to construct the Alkire-Foster measure by successively increasing to $33.3 \%$ the weight assigned to one particular dimension and distributing equally the remaining $66.6 \%$ to the rest of the dimensions. The results are highly robust to variations in the weighting structure. Based on the truncated inflated beta regression, while the size of the treatment effect is higher for three of the alterative weighting structures and lower for the other three, in all cases the coefficient on treatment continues to be statistically significant.

In a third set of tests we reestimated the treatment effect on $M_{0}$ using alternative values for the poverty threshold $\mathrm{k}$. The results based on the truncated inflated regression show that the effect of the TECHO programme on $M_{0}$ are statistically significant for all values of the poverty cut-off less than or equal to $60 \%$, indicating that this result holds for all reasonable values of the poverty threshold. The estimated treatment effects on $M_{0}$ are particularly large for values of $\mathrm{k} \leq 50 \%$. For values of $\mathrm{k} \geq 70 \%$ the truncated inflated regression model did not achieve convergence, likely due to the fact that only $4 \%$ of households (and none of the treated households) have $c_{i} \geq 0.7$. The results based on OLS regressions are quite similar to those based on the truncated inflated regression.

Based on these robustness tests, we can conclude that the finding that TECHO's emergency housing programme produces a large and statistically significant reduction in multidimensional poverty in dimensions related to the built environment holds up to variations in the criteria used to construct the multidimensional poverty measures.

\subsection{Decomposition of multidimensional poverty}

The Alkire-Foster measures have the dimensional breakdown property. $M_{0}$ can be expressed as the weighted sum of the post-identification dimensional deprivation rates:

$$
M_{0}=\sum_{j=1}^{d} w_{j} h_{j}(k)
$$


where $d$ is the number of chosen dimensions, $w_{j}$ is the relative weight assigned to dimension $j$ and $h_{j}(k)$ is the proportion of households identified as multidimensionally poor and simultaneously deprived in dimension $j$ (Alkire et al. 2015). The absolute contribution of the $j^{\text {th }}$ dimension to $M_{0}$ is $w_{j} h_{j}(k)$.

[Figure 3 near here]

Figure 3 shows the dimensional breakdown of $M_{0}$ for the control and treatment groups as well as the difference in the absolute contribution of each dimension between groups (numbers presented below each of the horizontal lines). The results illustrate, first, that the drop in $M_{0}$ is explained by substantial reductions in deprivation rates across all dimensions. This result is important because it means that the effects of the TECHO programme on the declustering of disadvantage is not being driven by reductions in deprivation in just a few dimensions, but rather that the improvements encompass multiple dimensions. Second, privacy, interpersonal relations and psychological health are the dimensions that contribute most to explaining the decline in multidimensional deprivation. Finally, after treatment, the security and interpersonal relations dimensions represent a small proportion of deprivation $(6.7 \%$ and $7.2 \%$ of the total, respectively) among the multidimensionally deprived. In contrast, although the TECHO programme produces a large decline in deprivation in the psychological health dimension, after treatment that dimension continues to represents nearly $30 \%$ of total multidimensional deprivation.

\section{Conclusions}

The interrelation between different forms of deprivation causes disadvantages to cluster together. In this paper we argue, therefore, that it is relevant to measure the effects of social programmes not only on individual outcome measures but also on the simultaneous occurrence or joint frequency of deprivation. We propose empirical strategies for 
evaluating treatment effects on the declustering of disadvantage using the Alkire-Foster method of multidimensional poverty measurement as an analytical tool. We develop criteria for constructing an Alkire-Foster measure comprised of multiple outcome indicators. In addition, we propose an econometric strategy-the truncated inflated regression model — for obtaining unbiased estimates of treatment effects on the adjusted headcount measure $M_{0}$, which adequately accounts for the measure's dual cut-off counting approach. We believe that this model can be usefully applied not only in impact evaluation, but also more broadly in the analysis of the determinants of multidimensional poverty.

We apply the proposed empirical strategies to the evaluation of the NGO TECHO's emergency housing programme in the informal settlements of Buenos Aires, Argentina. We construct an Alkire-Foster measure of deprivation in the following dimensions related to the built environment: physical health, psychological health, sleep, privacy, interpersonal relations and security. The empirical results show that the TECHO programme produces a large reduction in multidimensional deprivation in dimensions related to the built environment. The percentage of households identified as multidimensionally deprived declines substantially from $69 \%$ to $41 \%$ and the adjusted headcount measure falls by half. We show that these results are robust to variations in the selection of deprivation indicators, indicator weights and poverty threshold. These results suggest that the TECHO programme is reaching and producing a declustering of deprivation among the most deprived. It is, however, important to recognize that four out of ten participant households continue to be deprived in at least four indicators after receiving the TECHO house. This result provides clear evidence of the urgent need for public sector actions to improve habitat in informal settlements. 
Finally, the dimensional decomposition of the adjusted headcount measure proved to be a useful tool for analysing the effect of treatment on the structure of multidimensional disadvantage. The results illustrate that the TECHO programme produces a declustering of disadvantage that encompasses multiple wellbeing dimensions, rather than being concentrated in just a few indicators. The dimensions that contribute the most to reducing multidimensional deprivation in dimensions related to housing are privacy, interpersonal relations and psychological health. 


\section{References}

Alkire, S. and J. Foster. 2011. "Counting and Multidimensional Poverty Measurement." Journal of Public Economics 95(7-8): 476-487.

Alkire, S., J. Foster, S. Seth, M. E. Santos, J. M. Roche, and P. Ballon. 2015. Multidimensional Poverty Measurement and Analysis. Oxford: Oxford University Press.

Alkire, S. and S. Jahan. 2018. The New Global MPI 2018: aligning with the Sustainable Development Goals, OPHI Working Paper 121, University of Oxford.

Anderson, M. L. 2008. "Multiple Inference and Gender Differences in the Effects of Early Intervention: A Reevaluation of the Abecedarian, Perry Preschool, and Early Training Projects." Journal of the American Statistical Association 103(484): 1481-1495.

Angrist, J. D. and J. Pischke. 2009. Mostly Harmless Econometrics. Princeton, NJ: Princeton University Press.

Atkinson, A. B. 2003. "Multidimensional Deprivation: Contrasting Social Welfare and Counting Approaches." Journal of Economic Inequality 1(1): 51-65.

Bali Swain, R., and A. Varghese. 2009. "Does Self Help Group Participation Lead to Asset Creation?" World Development 37(10): 1674-1682.

Coleman, B. 1999. "The Impact of Lending in Northeastern Thailand." Journal of Development Economics 60: 105-141.

Decancq, K. and M. A. Lugo. 2012. Weights in multidimensional indices of wellbeing> An Overview. Econometric Reviews 32(1): 7-34.

Deininger, K. and Y. Liu. 2013. "Economic and Social Impacts of an Innovative SelfHelp Group Model in India." World Development 43: 149-163.

Duflo, E., G. Glennerster and M. Kremer. 2008. "Using Randomization in Development Economics Research: A Toolkit." In Handbook of Development Economics, edited by T. P. Schultz, and J. Strauss, 3895-3962, Amsterdam: North Holland.

Foster, J., J. Greer and E. Thorbecke. 1984. "A Class of Decomposable Poverty Measures." Econometrica, 52(3): 761-766.

Galiani, S., P. Gertler, R. Undurraga, R. Cooper, S. Martinez and A. Ross. 2016. "Shelter from the Storm: Upgrading housing infrastructure in Latin American slums." Journal of Urban Economics 96: 166-194.

Gray, L. and M. Hernandez Alava. 2018. "A command for fitting mixture regression models for bounded dependent variables using the beta distribution." The Stata Journal, 18 (1): 51-75.

Imbens, G. W. 2015. "Matching Methods in Practice: Three Examples." Journal of Human Resources 50(2): 373-419.

Kling, J. R., J. B. Liebman, and L. F. Katz. 2007. "Experimental Analysis of Neighborhood Effects." Econometrica 75(1): 83-119.

Loschman, C., C. Parsons and M. Siegel. 2015. "Does Shelter Assistance Reduce Poverty in Afghanistan." World Development 74: 305-322.

Masset, E. and J. García Hombrados. 2019. "Impact of the SADA-Northern Ghana Millennium Village Project on multidimensional poverty: A comparison of dashboard and index approaches" OPHI Working Paper 130, University of Oxford. 
Mitchell, A., J. Macció and D. Mariño Fages. 2019. "The Effects of Emergency Housing on Wellbeing. Evidence from Argentina's Informal Settlements." European Journal of Development Research 31(3): 504-529.

Muñiz Castillo, M. R. 2014. 2014. "Development Projects from Inside Out: Project Logic, Organizational Practices and Human Autonomy." Journal of Human Development and Capabilities 15(1): 79-98.

Narayan, D., R. Chambers, M. K. Shah and P. Petesch. 2000. Voices of the Poor: Crying Out for Change. Washington, DC: Oxford University Press for the World Bank.

Newman, S. J. 2008. "Does Housing Matter for Poor Families? A Critical Summary of Research and Issues Still to be Resolved." Journal of Policy Analysis and Management 27(4): 895-925.

Papke, L. E. and J. M. Wooldridge. 1996. "Econometric Methods for Fractional Response Variables with an Application to 401(k) Plan Participation Rates." Journal of Applied Econometrics 11(6): 619-632.

Pattanaki, P. K. and Y. Xu. 2018. "On Measuring Multidimensional Deprivation." Journal of Economic Literature 56(2): 657-672.

Pereira, G. H., D. A. Botter and M. C. Sandoval. 2012. "The Truncated Inflated Beta Distribution." Communication in Statistics - Theory and Methods 41(5): 907-919.

Pereira, G. H., D. A. Botter, and M. C. Sandoval. 2013. "A regression model for special proportions." Statistical Modelling 13(2): 125-151.

Pham, T. (2018). "The Capability Approach and Evaluation of Community-Driven Development Programmes." Journal of Human Development and Capabilities 19(2): 166-180.

Ravallion, M. 1992. "Poverty Comparisons: A guide to concepts and methods" Living Standards Measurement Survey Working Paper 88, The World Bank.

Richardson, H. 2015. "Using Final Ends for the Sake of Better Policy-Making” Journal of Human Development and Capabilities 16(2): 161-172.

Sen, A. 1985. "Well-being, agency and freedom: The Dewey lectures 1984." The Journal of Philosophy 82(4): 169-221.

Sen, A. 1992. Inequality re-examined. Oxford: Clarendon Press.

Sen, A. 1999. Development as freedom. Oxford: Oxford University Press.

Seth, S. and M. J. Tutor. 2019. "Evaluation of anti-poverty programs' impact on joint disadvantages: Insights from the Philippine experience" OPHI Working Paper 132, University of Oxford.

Simonelli, G., Y. Leanza, A. Boilard, M. Hyland, J. L. Augustinavicius, D. P. Cardinali, and D. E. Vigo. 2013. "Sleep and quality of life in urban poverty: the effect of a slum housing upgrading programme.” Sleep 36(11): 1669-1676.

Smithson, M. and J. Verkuilen. 2006. "A Better Lemon Squeezer? A MaximumLikelihood Regression with Beta-Distributed Dependent Variables." Psychological Methods 11(1): 54-71.

Song, S. and K. S. Imai. 2018. "Does the Hunger Safety Net Programme Reduce Multidimensional poverty? Evidence from Kenya." OPHI Working Paper 124, University of Oxford. 
TECHO. 2016. Relevamiento de Asentamientos Informales 2016. Accessed 15 January 2017. http://www.techo.org/paises/argentina/que-es-el-centro-de-investigacion-socialcis/www.techo.org.ar/relevamiento

Thomson, H., S. Thomas, E. Sellstrom, and M. Petticrew. 2009. "The Health Impacts of Housing Improvement: A Systematic Review of Intervention Studies From 1887 to 2007." American Journal of Public Health 99 (Suppl. 3): S681-S692.

United Nations Development Programme (UNDP) and Oxford Poverty and Human Development Initiative (OPHI). 2019a. How to Build a National Multidimensional Poverty Index (MPI): Using the MPI to inform the SDGs. Accessed 11 November 2019. https://www.undp.org/content/undp/en/home/librarypage/poverty-reduction/how-tobuild-a-national-multidimensional-poverty-index.html

United Nations Development Programme (UNDP) and Oxford Poverty and Human Development Initiative (OPHI). 2019b. Global Multidimensional Poverty Index 2019. illuminating inequalities. Accessed 20 August 2019. https://ophi.org.uk/wpcontent/uploads/G-MPI_Report_2019_PDF.pdf

Vaz, A., B. Malaeb and N. N. Quinn. 2019. "Evaluation of programs with multiple objectives: Multidimensional methods and empirical application to Progresa in Mexico." OPHI Research in Progress 55a, University of Oxford.

White, H. 2014. "Current Challenges in Impact Evaluation." European Journal of Development Research 26: 18-30.

Wolff, J. and A. de-Shalit. 2007. Disadvantage. Oxford: Oxford University Press. 
